\title{
Carnets
}

Revue électronique d'études françaises de l'APEF

Première Série - 1 Numéro Spécial | 2009

Cultures littéraires : nouvelles performances \& développement

\section{Culturas literárias e cultura digital: percursos, cruzamentos, desafios}

Fátima Outeirinho

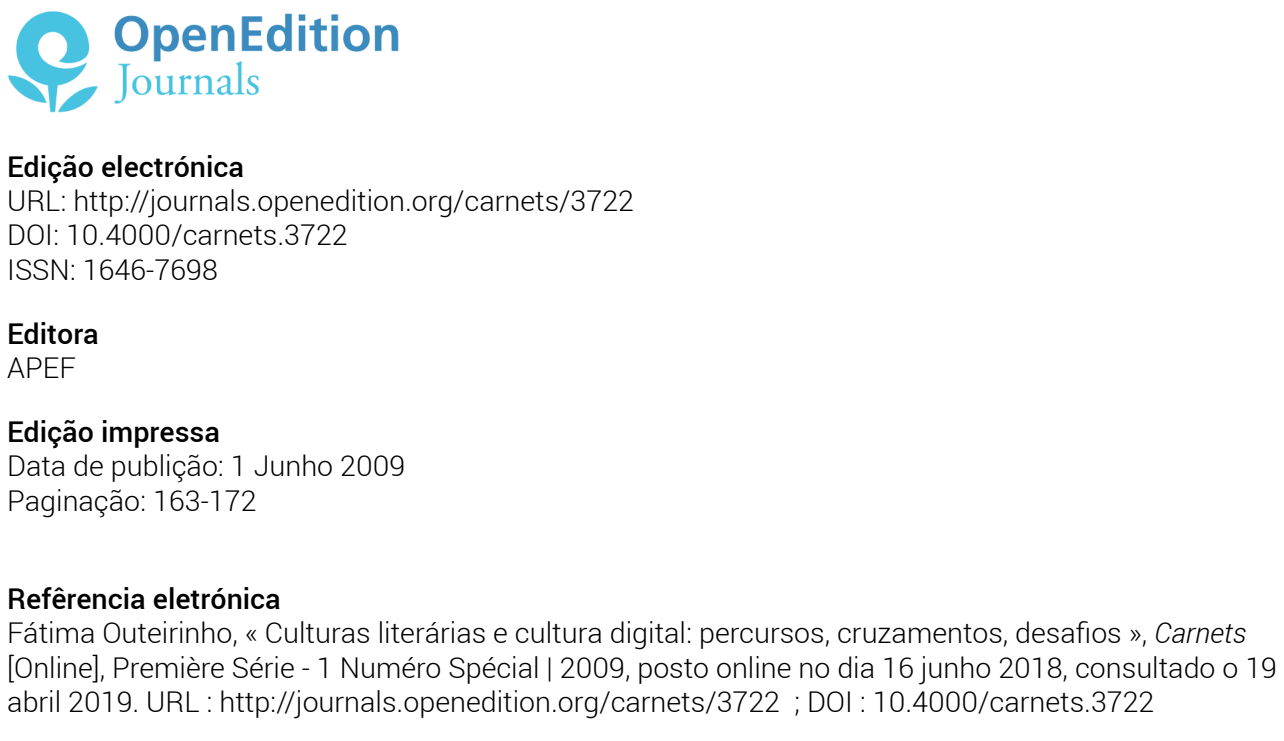

Licence Creative Commons

Carnets est mis à disposition selon les termes de la licence Creative Commons - Atribution - Pas

d'utilisation commerciale 4.0 International. 


\title{
CULTURAS LITERÁRIAS E CULTURA DIGITAL \\ Percursos, cruzamentos, desafios
}

FÁTIMA OUTEIRINHO

Universidade do Porto

outeirinho@letras.up.pt

\begin{abstract}
Resumo
Integrados que estamos numa "sociedad red" (Castells, 2001) e caracterizando-se a contemporaneidade pela experiência de uma cultura digital com consequências profundas nos mais diversos domínios da actividade humana e, por conseguinte, também no que toca à criação literária, aos Estudos Literários e ao ensino da Literatura, procurar-se-á, na presente comunicação, reflectir sobre percursos, cruzamentos e desafios que o hipermédia potenciou ou pode potenciar, ao nível da construção e difusão das culturas literárias, já que permite explorar um fazer artístico numa articulação com as novas tecnologias da informação e da comunicação e potencia novos modos de contacto e abordagem do facto literário do ponto de vista da recepção. Ora, pensar as práticas de leitura contemporâneas é tanto mais vital quanto, no domínio em que nos situamos, a leitura é ferramenta fundamental no processo de ensino-aprendizagem.
\end{abstract}

\begin{abstract}
Contemporary times are characterised by the experience of a digital culture with deep consequences in different fields: literary creation, Literary Studies or teaching literature. As a teacher and researcher living in a "sociedad red" (Castells, 2001), the main goal, in this present paper, is to contribute to the overall discussion related to the crossings and challenges that the hypermedia develops or can develop in what regards the construction and diffusion of literary cultures, because, in the one hand, hypermedia allows to explore artistic creation in a joint with information technologies and, on the other hand, it carries out new ways of approaching literary text. Within the teaching of literature is vital to think and to analyse contemporary reading practices since the reading is a basic tool in the teachlearning process.
\end{abstract}

Palavras-chave: Culturas literárias, Cultura digital, Estratégias de e-educação Keywords: Literary cultures, Digital culture, E-formation strategies 
Caracterizando-se a contemporaneidade pela experiência de uma cultura digital com consequências profundas nos mais diversos domínios da actividade humana e, por conseguinte, também no que toca à criação literária, aos Estudos Literários e ao ensino da Literatura, não é possível deixar de reflectir sobre percursos, cruzamentos e desafios que o hipermédia potenciou ou pode potenciar, ao nível da construção e difusão das culturas literárias, já que permite, por um lado, explorar um fazer artístico numa articulação com as novas tecnologias da informação e da comunicação, num processo que se pretende produtivo e enriquecedor e, por outro lado, potencia novos modos de difusão, de contacto e abordagem do facto literário do ponto de vista da recepção.

As mutações rápidas e consideráveis que se registam neste domínio devem pois interpelar todo aquele que se encontra integrado num contexto educativo. Assim, a presente comunicação encontra a sua origem no espaço em que me situo, um espaço universitário português no âmbito das Humanidades e, em particular, do ensino de uma literatura e cultura estrangeiras, assente então numa experiência empírica de docência que se confronta com novos suportes para a difusão da cultura escrita, incluindo a cultura literária, e novos modos de relação com essa cultura por parte dos estudantes. Este percurso reflexivo resulta ainda do reconhecimento de que as transformações em curso decerto condicionarão a sociedade do futuro já que, como observa Duarte Costa Pereira, tal quadro "leva também a que algumas competências percam importância (...), outras se transformem (escrita, leitura ${ }^{1}$, completamente diferentes no papel e no computador) e outras apareçam de novo" (Pereira, 2007:170-171).

Estando professor e estudante integrados numa "sociedad red" (Castells, 2001) ${ }^{2}$, na expressão vulgarizada, mas pertinente de Manuel Castells, o docente que, pela área científica em que se move, elege como objecto de estudo curricular um universo de textos literários e críticos e apela para uma relação estreita do estudante com a leitura, não pode eximir-se a repensar e reequacionar a sua prática pedagógica face à(s) prática(s) de leitura do tempo presente. Se considerarmos igualmente que no processo educativo o professor articula, numa relação triádica, conteúdos a trabalhar, sujeito aprendente e ancoragem social, então reflectir sobre tal problemática revela-se essencial no percurso do educador, pois daí pode resultar uma adequação ou mesmo revolução no que toca ao processo de ensino-aprendizagem, tal relação triádica implicando a assunção premente de novas práticas ou, pelo menos, de práticas renovadas.

\footnotetext{
${ }^{1}$ O negrito é da minha responsabilidade.

2 Cf. "Esa sociedad red es la sociedad que yo analizo como una sociedad cuya estructura social está construida en torno a redes de información a partir de la tecnología de información microelectrónica estructurada en Internet. Pero Internet en ese sentido no es simplemente una tecnología; es el medio de comunicación que constituye la forma organizativa de nuestras sociedades, es el equivalente a lo que fue la factoría en la era industrial o la gran corporación en la era industrial. Internet es el corazón de un nuevo paradigma sociotécnico que constituye en realidad la base material de nuestras vidas y de nuestras formas de relación, de trabajo y de comunicación" (Castells, 2001).
} 
Pensar estas questões é desde logo lembrar, por um lado, a instauração de novos modos de relação na tríade autor/texto/leitor em que o autor funciona como elo de uma cadeia colaborativa agora oculto nos bastidores, lembrar ainda o texto e o seu funcionamento hipertextual, reconhecer o leitor digital, de protagonismo crescente ou, nas palavras de Fernanda Bonacho, "the reader (...) simultaneously audience and actor" (Bonacho, 2007); por outro, lembrar o uso e exploração de um suporte digital com potencialidades no que toca à acessibilidade e rapidez no contacto com o facto literário e, por consequência, pensar os desafios colocados ao educador no sentido de desenvolver estratégias e-educativas (Aguirre, 2002), fomentando uma aprendizagem colaborativa situada e uma maior literacia digital.

Em 2001, Roger Chartier sublinhava que "Le nouveau support de l'écrit ne signifi[ait] pas la fin du livre ou la mort du lecteur. [...] Mais il impos[ait] une redistribution des rôles dans l'économie de l'écriture, la concurrence (ou la complémentarité) entre divers supports des discours et une nouvelle relation, tant physique qu'intellectuelle et esthétique, avec le monde des textes » (Chartier, 2001). Em número de Setembro de 2006, a revista L'Histoire oferecia aos leitores um dossier no qual se procurava responder à pergunta: "Les étudiants lisent-ils encore?" (L'Histoire, 2006: 71) Num dos testemunhos recolhidos, um professor a dado passo afirmava: "Nous n'avons pas de culture commune. J'ai le sentiment d'être audelà d'une mutation culturelle" (idem: 72). O sentimento idêntico que alguns educadores poderão experimentar, e nomeadamente no que toca a um comércio pessoal com o livro, prende-se com o facto de terem vivido o reinado do livro, a que sucedeu o reinado da fotocópia, confrontando-se agora com a dinastia mais recente protagonizada pelo documento on-line. Com efeito, vários são os recursos literários existentes na WWW: livros electrónicos, revistas literárias ou sobre literatura, bibliotecas virtuais, bases de dados, cursos on-line, sites com informação monográfica sobre grandes criadores literários, fóruns ou blogs de temática literária, não esquecendo a presença e importância crescente dos wikis. Todas estas ferramentas e enorme jazida informativa não podem ser desaproveitadas pelo educador até porque, em princípio, está perante um público mais familiarizado com as novas tecnologias da informação e da comunicação ${ }^{3}$ e há que tirar partido desse facto.

A considerável oferta de informação e o modo como é colocada à disposição do utilizador estruturam-se porém numa mudança de paradigma que se prende com uma deslocação: do centro de produção para um novo centro, o do leitor, o da recepção,

\footnotetext{
${ }^{3}$ Em estudo de 2004, encomendado pela APEL (Associação Portuguesa de Editores e Livreiros), sobre a compra de livros e hábitos de leitura em Portugal, podem-se encontrar os seguintes números indiciais de uma cultura digital: $42 \%$ dos entrevistados têm computador em casa e $36 \%$ usam computador fora de casa, sendo que a posse e utilização se situa particularmente no grupo com menos de 35 anos e o seu índice mais levado se regista na faixa entre os 15 e os 19 anos. Também $25 \%$ do total de respondentes que utilizam computador declararam procurar informação sobre livros na internet - $9 \%$ no total do universo de amostra (http://www.apel.pt/gest_cnt_upload/editor/File/apel/estudos_estatisticas/Habitos\%20de\%20Leitura\%202004.pdf).
} 
parecendo funcionar o autor tão só como o scriptor que dá lugar na ribalta digital ao texto e ao seu leitor.

O texto, ou mais rigorosamente o hipertexto, apoiado num processo cognitivo, o pensamento associativo a trabalhar a continuidade e a similaridade, permite associações tendencialmente em expansão de diferentes e/ou múltiplas informações. Se tomarmos como exemplo o funcionamento hipertextual do hipermédia, reconhecemos que apela para um utilizador activo que a todo o momento deve proceder a escolhas, construindo deste modo um percurso singular de relação com o texto, com frequência articulado com imagem, som ou vídeo. Há que reconhecer então uma diluição quanto aos papéis de emissor e receptor ${ }^{4}$, face a um texto multidimensional num percurso de escolhas múltiplas em que o leitor surge como entidade unificadora de protagonismo essencial mas fugaz, condição da revelação textual.

Com efeito, numa cultura digital, o hipertexto oferece-se enquanto texto dinâmico, no qual o leitor navega através de links, criando um contexto semântico para o qual contribuiu de forma activa e o autor, tal como era tradicionalmente concebido, parece ficar na sombra. O lugar primacial é agora outorgado ao texto, à interactividade, ao papel activo do fruidorutilizador - o leitor digital da actualidade - que autores como Borges (2000) anunciavam décadas antes ${ }^{5}$ da criação do termo hipertexto cunhado por Ted Nelson e que a WWW na década de 90 ajudou a desenvolver e expandir.

\section{Práticas de leitura hoje}

Neste quadro de uma cultura digital, muito esquematicamente traçado, há que considerar as práticas de leitura de hoje. É já banal a preocupação e o lamento em torno da diminuição da prática de leitura junto dos jovens. A emergência de um grande foco de investigação, em torno de atitudes, práticas e hábitos de leitura, continuadamente explorado a partir do início da década de 90, dá desse facto claro testemunho. Os estudos feitos para Portugal concluem que "a leitura é uma prática valorizada positivamente; do mesmo modo, que existe uma atitude claramente favorável para com a leitura" (Castro/Sousa, 1996) porém também verificam que funciona como prática minoritária pela razão maior de os jovens preferirem outras actividades em termos de ocupação de tempos livres (ibidem) ${ }^{6}$. Observa-

\footnotetext{
${ }^{4}$ Como em síntese afirma Helena Buescu, o "texto reconhece-se e mostra-se como lugar de transitividade de sentidos adentro de uma determinada comunidade que, entre outras coisas, partilha formas de comunicação socialmente instituídas e reguladas. Dito de outro modo, o texto sabe e mostra que vem de alguém e vai para alguém e que nesse movimento se jogam relações complexas de partilha e alteridade" (Buescu, 1998: 25).

${ }^{5}$ Da literatura à música ou à pintura, vários têm sido os criadores a traçar percursos de experimentação, através de modos combinatórios, por vezes algorítmicos, apelando para um fruidor-utilizador activo que explora a interactividade.

${ }^{6}$ Nas razões indicadas para não ler, surge, em $2^{\circ}$ lugar, o pouco interesse e, em $3^{\circ}$ lugar, o preço do livro (Castro/Sousa, 1996). Os autores do estudo salientam a desvalorização objectiva da leitura.
} 
se portanto uma nítida discrepância entre o discurso sobre a prática de leitura e uma prática efectiva. Os estudos sociológicos levados a cabo quer em Portugal quer noutros países europeus, salientam uma diminuição progressiva da prática de leitura desde os anos 80 , não justificada contudo por práticas culturais substitutas. Contrariamente ao que diz o senso comum, o processo de recessão aconteceu previamente à vulgarização e banalização da internet. Os estudos revelam ainda que os contextos de origem e inserção social ou a pertença etária não explicam os resultados obtidos ${ }^{7}$. Na verdade, o que parece suceder é uma "quebra do valor emblemático do livro, em virtude da generalização do seu consumo e da massificação do público-leitor" (Fernandes et alii, 1998: 98). Registe-se ainda que a diminuição da prática de leitura é maior junto de uma franja masculina estudantil do que junto de uma franja feminina ${ }^{8}$.

A preocupação com tal estado de coisas tem redundado na implementação de acções que visam a promoção da leitura. No caso português, lembro a criação do designado Plano Nacional de Leitura, lançado em Junho de 2006 "com o objectivo central de elevar os níveis de literacia e reforçar as práticas de leitura dos portugueses"9. Dirigido de modo particular a crianças que frequentam a educação pré-escolar e o ensino básico, tem ainda como público-alvo agentes como educadores de infância e professores, pais e encarregados de educação, bibliotecários, mediadores e animadores de leitura. Com o objectivo de eficácia e de vir a obter resultados válidos, o PNL elege como campos de intervenção bem diversificados, áreas que vão desde o jardim-de-infância até à família ${ }^{10}$. A necessidade experimentada em investir num conjunto de acções de promoção da leitura, já a partir de uma etapa precoce, reflecte a necessidade de combater e prevenir uma secundarização e diminuição da prática de leitura, com consequências sociais várias.

$\mathrm{Na}$ área em que me situo - o espaço universitário - poderei dar testemunho de sinais preocupantes, mas que prefiro assumir como interpelantes para a minha prática docente, no que ao papel e importância da leitura diz respeito junto de um público estudantil. Salientaria apenas dois desses sinais com os quais contacto no meu quotidiano: verifico, por exemplo, que a preocupação, por parte do estudante, em fazer uma biblioteca pessoal parece atenuada; tenho também vindo a experimentar a dificuldade, crescente ao longo dos anos, em fazer ler, para uma mesma unidade curricular, vários livros de leitura integral.

\footnotetext{
7 "As variáveis classe social de origem e grupo etário não parecem assumir a configuração de variáveis suficientemente discriminatórias, não se detectando assim diferenciações assinaláveis. " (Fernandes, 1998:103). ${ }^{8} \mathrm{O}$ documento "Estudo de hábitos de leitura e compra de livros", e por nós acima referido, dá conta desse mesmo facto.

${ }_{9}^{9} \mathrm{Cf}$. http://www.planonacionaldeleitura.gov.pt/index.php?s=textos\&pid=1511\&tab1id=1485\&tab2id=1499.

${ }^{10}$ Escolas, bibliotecas escolares e públicas, instituições que possam promover a leitura, instituições culturais, educativas, de solidariedade, espaços não convencionais de leitura e meios de comunicação social são áreas de intervenção também consideradas por esta iniciativa de promoção da leitura.
} 
Em 1996, Rui Castro e Maria de Lourdes Sousa observavam, em estudo sobre a leitura, que

Pais e professores parec[iam] entender que os leitores são feitos de uma vez para sempre nos primeiros anos de escolaridade e que a partir daí a questão é tão só a de usar esse ganho. No entanto, dada a perda de leitores observada após o 3ํㅗciclo, parece importante que as escolas assumam que os estudantes mais velhos devem [estar] em contacto constante com actividades de promoção da leitura, principalmente através da disponibilização de materiais de leitura apelativos (Castro/Sousa, 1996).

Reiterando tal advertência, considero, de resto como tantos outros, que o leitor é sempre uma realidade em construção; por consequência, o professor é alguém que contribui para esse work in progress e contrariando algum cepticismo expresso por George Steiner em Elogio da Transmissão (Steiner, 2004: 75-76), advogo que, nesta etapa de formação, ainda não é tarde para abrir horizontes ou fazer sonhar novos horizontes, entrando em diálogo com e a partir dos textos.

\section{Como chegar aos leitores de hoje, também leitores digitais: alguns caminhos}

Se actualmente a leitura é ainda uma ferramenta fundamental no processo de ensino-aprendizagem, no âmbito dos estudos literários - e não apenas neste domínio -, não só é, evidentemente, via de acesso ao conhecimento como é cumulativamente o processo que permite tomar contacto com manifestações criativas de uma dada literatura e cultura e, por consequência, pode também ser objecto de fruição estética. Num curso de literatura e cultura, a leitura é actividade fundamental mesmo quando já se recorre a recursos outros facilitadores ou indutores da aprendizagem e, no que ao estudo - forma particular de ler diz respeito, tal facto é ainda verdadeiro. Perante um menor contacto com o objecto livresco, há que tomar consciência do desenvolvimento de uma outra oferta de leitura e da multiplicação de práticas culturais outras. Não por acaso, a indústria cultural foi implementando, desde a última década do século $X X$ até hoje, uma diversificação de suportes de leitura. Lembre-se o mercado livreiro que aposta grandemente numa reorientação dos objectos de leitura, colocando-os à disposição do consumidor ${ }^{11}$. Como já era salientado em meados da década de 90 , os próprios salões do livro foram dando cada vez mais espaço de exposição a suportes multimédia ${ }^{12}$.

\footnotetext{
${ }^{11}$ Com efeito, o leitor actual tem ao seu dispor, por exemplo, o livro em suporte papel tradicional, mas também em áudio ou mesmo em formato digital com o e-book.

${ }^{12}$ A obra Le Livre: la fin d'un règne, de Fabrice Piault, ergue-se em torno deste mesmo facto.
} 
Hoje em dia, na era do audiovisual, é ainda lícito falar de uma prática de leitura extensiva, mas tal significa considerar um manuseio dos livros que pode ser condicionado por uma leitura zapping (Piault, 1995:32), na expressão de Fabrice Piault, à semelhança do que acontece com a situação vivida pelo telespectador pois, como afirma Sophie Barluet, "On lit désormais comme on circule sur Internet : de manière éclatée et dispersée » (apud L'Histoire, 2006 :73). Falar duma prática de leitura extensiva significa considerar também o manuseio de diversos suportes de leitura cada vez mais banalizados e, por consequência, novas formas de relação com a cultura escrita.

Assim, cabe ao professor procurar uma solução de compromisso entre os conteúdos que a leitura permite trabalhar e que considera fazerem parte dum núcleo duro e os interesses do estudante decorrentes do seu constructo individual que o educador deve procurar aproveitar, para que haja um envolvimento afectivo entre leitor e texto, atendendo ao facto de que o leitor compreende o que lê não apenas através de estruturas cognitivas, mas também através de estruturas afectivas. Na era da imagem, mas ainda da cultura escrita e face à leitura, o professor é então aquele que aposta na dimensão cognitiva e na dimensão afectiva da leitura, e esta não vem necessariamente em segundo lugar já que poderá ter consequências produtivas ao contribuir para uma memória de leitura do estudante. No que à dimensão cognitiva diz respeito, trata-se de apostar na cognição enquanto processo heurístico e de ver no estudante um "construtor da aprendizagem" (Pereira, 2007:197). Importa fomentar uma atitude activa por parte do estudante que, de resto, deve caracterizar todo o processo de ensino-aprendizagem de que o estudante será o centro.

$\mathrm{Na}$ verdade, interessa um leitor activo que, pelo menos progressivamente, adquira competências críticas. O leitor que no contexto educativo em apreço se espera encontrar ou vir a encontrar, ao longo do processo formativo num tempo diferido, é já o intérprete capaz de desenvolver uma aproximação hermenêutica ao texto. Trata-se pois de fomentar um pensamento e uma atitude interactivos ao longo do percurso educativo. Ler, neste estádio, deverá implicar não apenas uma compreensão literal e inferencial de um dado texto, mas também uma compreensão avaliadora e crítica de que idealmente não deve estar ausente o prazer da leitura. Adoptando uma perspectiva construtivista em que "los alumnos aprenden mejor mediante la construcción activa de ideas en vez de recibir información pasivamente sin reprocesarla" (Skar; 2002:18), trata-se de gerar uma competência e não apenas de transmitir informação como tradicionalmente sucedia.

Nesse sentido, propostas como a de Joaquín Aguirre Romero e que apontam para a utilização de hipertextos numa dinâmica de trabalho de grupo (Aguirre, 2002), são estratégias de valor heurístico não negligenciável, com a vantagem acrescida de fomentarem uma aprendizagem colaborativa. Este tipo de abordagem pode permitir 
"representar que los textos no son unidades cerradas" (ibidem), permitindo ainda, por exemplo, tomar consciência, pela exploração do funcionamento associativo do hipertexto, da pluralidade de itinerários a eleger nos caminhos da leitura de um dado texto literário. Não negligenciável é a relação próxima com os textos que tal estratégia implica e eventualmente fazendo descobrir o já referido prazer da leitura. Forma ainda de conferir protagonismo ou pelo menos poder decisório ao estudante é a sucessiva motivação para a descoberta de recursos literários em torno de uma questão, de um autor, a partir de um desafio feito pelo professor, não podendo este recusar a tarefa de filtragem e monitorização na relação do estudante com a oferta em circulação na Web.

Outra estratégia possível de adopção passa pela criação de chats e/ou fóruns ${ }^{13}$ que explorem a apetência dos estudantes no que toca à adesão às redes sociais disponibilizadas na Web, funcionando como uma extensão e complemento do que é desenvolvido em sala de aula. O desenvolvimento e/ou aproveitamento de plataformas colaborativas poderá também fomentar uma atitude interveniente por parte do estudante. Qualquer que seja a estratégia encontrada, importa afinal desenvolver o gosto pela leitura bem como competências de autonomia e de auto-aprendizagem, podendo o professor funcionar como timoneiro de novas viagens textuais.

Trata-se, deste modo, de explorar um aproveitamento pedagógico de novos suportes de leitura, usando recursos digitais facilitadores ou indutores da aprendizagem, procurandose igualmente por esta via combater a diminuição da prática de leitura que, na actualidade se revela minoritária junto dos jovens, jogando na sua promoção, com consequências ainda na construção de uma memória de leitura e na criação de competências que acompanharão o estudante no seu percurso de vida, com implicações sociais alargadas.

A breve reflexão aqui apresentada resulta da consciência em implementar uma aprendizagem situada (Pereira, 2007:528ss). Assim, tendo em conta um novo contexto de onde emergem novas práticas culturais e novos modos de relação com a cultura escrita, procurei reflectir sobre uma intervenção pedagógica que muito embora esteja a ser perspectivada a partir do ensino-aprendizagem em unidades curriculares ligadas ao estudo duma literatura e cultura estrangeiras, poderá trazer, pese embora a difícil mensurabilidade da extensão de tal acção, reflexos positivos sobre práticas de leitura a médio ou a longo prazo. Com efeito, trata-se de propor e implementar uma acção induzida que se espera que venha a ser voluntária e espontaneamente assumida no futuro. Ao defender o aproveitamento do que as novas tecnologias da informação e da comunicação nos oferecem enquanto ferramenta pedagógica, trata-se igualmente de desenvolver uma literacia digital e explorar não apenas recursos educativos, mas também estratégias e-educativas.

\footnotetext{
${ }^{13}$ A existência de fóruns nas plataformas de e-learning, desde que regularmente geridos e moderados, têm vindo a revelar-se espaço procurado e de encontro por parte dos estudantes.
} 
Do reinado do livro e da fotocópia para o reinado do documento electrónico, o educador é então aquele que se dispõe a cruzar culturas, da sua para a do estudante, saindo do seu território para ir ao encontro do outro e face à dessacralização do livro e da leitura, perante a desvalorização do poder de legitimação que uma cultura literária durante tanto tempo exerceu, o professor pode e deve assumir-se como leitor também ele em construção e nessa medida só pode fazer o "elogio da dificuldade" (Steiner/Ladjali, 2004), força motriz num processo de ensino-aprendizagem. 


\section{Bibliografia}

AGUIRRE, Joaquín Romero (2002). " Ciencia, Humanismo, Humanidades y Tecnología”, Espéculo. Revista de Estudios Literarios, http://www.ucm.es/info/especulo/numero19/humanism.html [disponível em 30 de Setembro de 2008].

AGUIRRE, Joaquín Romero (2002). "La Enseñanza de la Literatura y las Nuevas Tecnologías de la Información", Espéculo. Revista de Estudios Literários, http://www.ucm.es/info/especulo/numero21/eliterat.html [disponível em 30 de Setembro de 2008].

APEL (2004). "Estudo de Hábitos de Leitura e compra de livros", http://www.apel.pt/gest_cnt_upload/editor/File/apel/estudos_estatisticas/Habitos\%20de\%20Leitura \%202004.pdf [disponível em 30 de Setembro de 2008].

BONACHO, Fernanda (2007), "The Erlebnis of New Reading", http://www.cecl.com.pt/workingpapers/content/view/22/53/ [disponível em 1 de Junho de 2008].

BORGES, Jorge Luís (2000). "Análise da obra de Herbert Quain", Ficções, trad. José Colaço Barreiros, Linda-a-Velha, Abril/Controljornal, col. "Biblioteca Visão", pp. 45-49.

Buescu, Helena (1998). Em Busca do Autor Perdido. Histórias, concepções, teorias, Lisboa, Edições Cosmos.

CASTELLS, Manuel (2001). "Internet y la Sociedad Red", La Factoría, http://www.cabuenes.org/03/documentos/cursos/globalizacion/bloque2/glob_blq2_08.pdf [disponível em 1 de Junho de 2008].

CASTRO, Rui Vieira e Mํㅡㄹ de Lourdes Dionísio de Sousa (2000). "Hábitos e atitudes de leitura dos estudantes portugueses", http://www.ectep.com/literacias/orientacoes/ensaio/01.html [disponível em 1 de Junho de 2008].

CHARTIER, Roger (2001). "Lecteurs et Lectures à l'âge de la textualité éléctronique", http://www.texte.org/conf/index.cfm?fa=texte\&ConfText_ID=5 [disponível em 1 de Junho de 2008].

Fernandes, António Teixeira (1998). Práticas e Aspirações Culturais. Os Estudantes da Cidade do Porto, Porto, Edições Afrontamento/Câmara Municipal do Porto.

L'Histoire (2006), Paris, Société d'Éditions Scientifiques, sept., ㄲo 312.

PereIRA, Duarte Costa (2007). Nova Educação na Nova Ciência para a Nova Sociedade. Fundamentos de uma Pedagogia Científica Contemporânea, vol.I, Porto, Editora UP.

PIAULT, Fabrice (1995), Le Livre: la fin d'un règne, Paris, Éditions Stock.

"Plano Nacional de Leitura",

http://www. planonacionaldeleitura.gov.pt/index.php?s=textos\&pid=1511\&tab $1 \mathrm{id}=1485 \&$ tab2id $=1499$ [disponível em 30 de Setembro de 2008].

SKAR, Stacey Alba D. (2002). "Pedagogia y tecnologia en educación norteamericana: vínculos con la literatura y la lectura", El Fomento del Libro y la Lectura, Chaco, Fundación Mempo Giardinelli, pp.11-21.

STEINER, George e Cécile Ladjali (2004). Elogio da Transmissão. O professor e o aluno, Lisboa, Dom Quixote. 